\title{
Problems and Countermeasures to be solved in the emergency relief work of Red Cross Society of China
}

\author{
Zhu Jinyu \\ Liaoning Academy of Governance,Shenyang,Liaoninng,China \\ 350082105@qq.com \\ Zhu Jinyu
}

Keywords: Red Cross Society of China; Emergency relief; countermeasure

\begin{abstract}
In recent years, The Red Cross has played an irreplaceable role in the disposal and rescue of sudden events such as natural disasters, accident disasters and so on. Take practical action to "divide the worries for the government and solve the difficulties for the people", Protruding as an assistant to the government's humanitarian field. However, some problems that need to be solved in the Red Cross Society's own existence and development have become the factors restricting its further improvement of emergency rescue capability, In this paper, we adhere to the problem oriented, try to solve these problems and put forward the corresponding countermeasures and suggestions, and strive to provide reference for the sustainable and healthy development of the emergency relief work in the Red Cross Society.
\end{abstract}

\section{我国红十字会在应急救灾工作中亟待解决的问题及对策研究}

\author{
朱荩予 \\ 辽宁行政学院, 沈阳, 辽宁, 中国 \\ 350082105@qq.com \\ 朱荩予
}

关键词：红十字会; 应急救灾; 对策

中文摘要. 近几年，红十字会在自然灾害、事故灾难类等突发事件处置与救援中发挥了不可 替代的作用, 以实际行动 “为政府分忧, 为百姓解难” , 凸显出作为政府人道领域助手的作 用。然而红十字会自身存在与发展中的一些亟待解决的问题成为制约其进一步提升应急救灾 能力的因素, 本文坚持以问题为导向, 力求破解这些难题并提出相应对策建议, 致力于为推 动各地红十字会应急救灾工作持续、健康发展提供可借鉴的做法。

\section{1. 引言}

近年来, 红十字会通过普及中国红十字会灾害管理信息系统, 推动当地红十字会备灾中 心 (物资库) 建设, 逐步修订和完善应急预案, 建立和规范应急救援队伍, 坚持开展应急救 援培训和演练等举措, 不断加强应急体制机制建设, 应急救灾能力显著提高, 并在自然灾害、 事故灾难类突发事件的应急处置与救援中发挥了不可替代的作用, 做出了重要贡献。然而各 地红十字会自身存在与发展中的一些问题成为制约应急救灾工作的瓶颈因素, 破解这些难题, 深入研究制约红十字会应急救灾工作中的因素, 提出相应对策建议成为进一步推动红十字会 应急救灾工作有序进行和健康发展的当务之急。 


\section{2. 当前红十字会在应急救灾工作中亟待破解的问题}

\section{1 应急资金缺乏}

主要表现为筹资能力不足，政府财政拨款仍然是红十字会管理经费乃至应急救灾活动经 费的主要来源，公益性和盈利性筹资手段所获得的红十字基金少之又少，受地方经济发展新 常态和地方经济发展速度放缓影响, 政府拨款仅供维持日常机构运转, 不能完全保障应急救 灾资金之需。

\section{2 人员专业化水平不高}

主要体现为红会工作人员和志愿者队伍缺乏有效的管理, 应急救灾能力不强; 缺少专业 的应急装备。

\section{3 应急救灾运输协调机制不够完善}

各地区红会基本都建立了本地物质储备库，但普遍存在物资储备种类单一、调配不畅问 题：大部分是存放时间不宜过长且容易采购的棉被、棉衣、棉服、帐篷，造成资源极大浪费。 而大量急需物品未进行储备。应急物资管理信息化建设较慢, 在紧急情况下, 物资调配不够 流畅。

\section{4 应急宣传力度不够}

红十字会社会影响力和推广力不强。红十字会本身价值理念一直没有明确定位使得社会 公众对其了解和理解不够深入，加之日常文化宣传不足、传播不广，因此并未形成能够凝聚 全社会的精神力量。红十字文化鬼米力并没有在社会层面得到广泛的推广并形成强烈的感召力, 影响了社会对红十字文化的认知度。其次, 现阶段良好的社会慈善公益环境尚未形成。影响 力和渗透力的不足影响红十字会应急救灾能力的发挥, 尤其体现为应急知识宣传教育不足等 方面。

\section{3. 进一步发挥红十字会在应急救灾工作中作用的对策建议}

\section{1 创新多元化资源动员路径}

作为国际性组织的红十字会，有坚实的国际、国内法律为其护航，这是红十字会区别于 其他公益机构的独特优势。红十字会公益筹资的空间和路径将会伴随社会的发展和社会公众 责任感的逐步提高得到更广泛的扩展。因此，除 “临灾呼吁”、“募捐” 等常规资源动员方式 以外，红十字会应开辟更多资源动员路径包括：微博公众号及短信、红十字品牌、网络募捐、 明星慈善效应、寻找战略伙伴、基金以及市场营销等方式。红十字会的募捐不应仅仅理解为 筹款、捐款，而是募集各种资源：包括构建关系资源、网罗各类专业人才资源和获取广泛的 信息资源等。在市场环境日趋变化的情况下, 红十字会募捐活动的多元化无疑是其最好的选 择。

\section{2 提升人员有效管理举措}

1. 不断提升红十字会工作人员的职业素养和专业水平。红十字会能否有效参与政府应急 管理的关键在于应急工作者是否具有牢固的危机意识、高效的应急决策和行动能力。红十字 会需要进一步提升工作人员职业素养和专业水平, 不断提高他们的危机意识和业务能力, 通 过正向激励以及事后追责等管理机制、通过积极开展各种学习培训和实战演练活动, 努力建 设一支乐于奉献、敢于担当、爱岗敬业、业务过硬的红十字会工作人员队伍。专业资源才是 发挥更高工作效能的基础和保障, 只有充分有效地调动专业资源, 红十字会在应急救灾工作 中才会保持高效能运作模式。 
2. 进一步加强志愿者管理有效性, 最大程度调动其积极性。针对红十字会志愿者队伍普 遍存在的 “人员午杂、难于管理” 的问题。必须致力于建立一支统一、高效、专业的志愿者 队伍, 着重做好以下几个方面工作：（1）提供高质量的培训。志愿者参加服务之前应当先接 受培训, 对志愿者资源的培养是有效实现红十字会组织目标的必要条件。通过培训, 使志愿 者了解并掌握红十字会的活动宗旨以及所要实现的预期目标。红十字志愿者的培训内容细化 为志愿者文化培训、应急技能培训、资金募集、以及管理模式和管理技能培训等。（2）提供 必要的待遇。志愿者在应急救灾工作中服务的实质是对他人提供救助服务而不索取报酬。但 自愿者的付出和劳动必须应该得到应有的尊重和应有的鼓励及待遇。对于一些如通讯费、交 通费、基本食宿乃至最低生活费用等与应急救灾活动紧密相连且必然产生的费用包括出于救 灾中生命安全考虑为志愿者缴纳必要的人身保险等救灾活动资金, 应成为考核红十字会对志 愿者管理工作的重要指标。（3）满足志愿者的深层次精神需求。红十字会作为志愿者的组织 者和管理者, 应当采取措施使志愿者深切的感受到自己无私的奉献和付出是被社会所认可的、 被公众所尊重的。红十字会必须不断满足志愿者的精神需求。如对在应急救灾中表现突出的 志愿者通过网络媒体、电视、广播和报纸等多种传播方式宣传他们的事迹, 或联合政府部门在 公开场合加以表扬或表彰, 及时给予志愿者必要的精神和物质奖励, 表明国家、全社会对志 愿者付出和劳动的认可, 这样会激励更多的志愿者投入和献身红十字会工作, 加入应急救灾 活动, 更有效地实现红十字人道主义救援目标。

\section{3 加强应急救灾协调联动工作机制建设}

应急救灾工作, 政府是主导, 红十字会协调好与政府的关系极为重要。红十字会应建立 与政府相关职能部门定期联络、有效沟通的长效工作机制。例如定期召开联席会议: 根据各 部门应急职责和任务, 进一步明确各自的工作职责和范围, 确保在灾害发生时各司其职、协 调高效，提高救灾的实效性和有效性。红十字会应加大与地方政府党委的密切联系。

\section{4 创新应急物资储备及运输方式方法}

改变现有僵化的红十字会应急物质储备方式，创新物质储备及运输的方式方法关系着应 急救灾工作的效能。各地区红十字会在建立本地区物质储备库的基础上, 应逐步建立救灾物 质的紧急调用机制, 变革物质储备方法。救灾物质储备的类型和数量必须根据本地易发生各 类灾害的情况进行安排。当前, 实物储备仍然是各级红十字会应急物资储备的主要形式, 未 来应该致力于与企业以契约形式订立的应急物资合作事宜, 对一些特殊的应急救灾物质着重 开展以生产能力储备为主要方式的应急物资储备管理方式。这种储备方式不仅使物资储备更 加灵活，使用效率更高，而且有利于降低物资储备的成本。

未来, 红十字会还应致力于打造和建设隶属于红十字会的物资运输队伍, 而不再依附于 企业。运输队伍的建立有利于红十字会在应急救灾中, 及时高效运送物资, 保障物资运送和 到达时效。

\section{5 创新宣传形式}

红十字文化应该加大对外宣传的力度, 让社会各界了解红十字文化, 认可我们的工作, 取得社会的理解和支持。

1. 充分利用报刊、电视台、网络等新闻媒体，报道红十字会的工作。传播正能量，通过 媒体打通红十字文化通向全社会的传播渠道。

2. 通过新型媒体传播方式，提高红十字文化传播效率。用新的传播途径扩大宣传的影响 力, 如政务微博、微信公众号等。广泛宣传红十字文化精神、红十字工作的内容, 形成辐射 效应, 提高红十字会的影响力。

3. 利用各种课堂, 宣传红十字文化。建议在党校、行政学院主体班次开设红十字知识培 训专题和应急救护培训专题, 在社区、企业、学校不定期免费进行应急救护培训, 让红十字 
文化走向社会, 扩大宣传面和影响力。让社会知道红十字会主要工作职能, 做了哪些工作, 认可其工作，进而支持其工作，让 “人道、博爱、奉献” 的精神成为大家的自觉行动。

\section{References}

[1] Golden Bridge. The Red Cross Society of Shandong Province set up "N" for donors. The Red Cross newspaper of China is from 2006 to June 2006 (1).

[2] Total red. Red Cross Society of China [N]. China Red Cross newspaper, 2012 - 06 - 08 (1).

[3] Yang Hongxing. Summary of Charity Actions of the Red Cross Society of China in Combatting the“ SARS" Bat-tle. Cultural Science,2007(6).

[4] Beijing Planning Office of Philosophy and Social Science.Crisis Management Report. Beijing:Tongxin Press,2006. p93.

[5] Red Cross Society Law of People' s Rebuplic of China.Article 22nd.

[6] Red Cross Society of China. http://www.redcross.org.cn/hhsy/hhsy.htm. 